\title{
Use of diatom motility features as endpoints of metolachlor toxicity
}

\author{
Coquillé Nathalie ${ }^{1,2,3}$, Jan Gwilherm ${ }^{1}$, Moreira Aurélie ${ }^{1}$, Morin Soizic ${ }^{1, ~ *}$
}

${ }^{1}$ Irstea, UR EABX, F-33612 Cestas, France.

2 Univ Bordeaux, Lab Phys Tox Chim Environm, UMR EPOC 5805, CNRS, F-33405 Talence, France.

${ }^{3}$ IFREMER, Lab Ecotoxicol, F-44311 Nantes 03, France.

* Corresponding author : Soizic Morin, tel.: +33 557892726 ; email address : soizic.morin@irstea.fr

\begin{abstract}
:
Many recent ecotoxicological studies suggest a relationship between freshwater contamination and increasing abundances of motile diatoms (potentially able to move). The capacity to escape would present advantages to species in polluted environments. However, actual motility as a response to toxicants had not been described and required experimental validation. We designed a specific experiment to assess how a field-isolated diatom (Gomphonema gracile) distributes energy to in situ resistance (increased population growth or photosynthesis) and escape (behavioral changes), when exposed to increasing concentrations of the herbicide metolachlor. We report here the dose-time dependent responses of $\mathrm{G}$. gracile populations. They coped with low contamination by resisting in situ, with early hormetic responses highlighted by stimulation of chlorophyll-a fluorescence. At a higher dose, harmful impacts were observed on growth after a few days, but an earlier behavioral response suggested that higher motility (percentage of motile individuals and mean distance crossed) could be involved in escape. Our findings bring new arguments to support the implementation of real measurements instead of motility traits in toxicity assessment. Specifically, motion descriptors have been used as early-warning indicators of contamination in our study. Further works should address the reliability of these endpoints in more complex conditions (interspecific variability, behavior in the field).
\end{abstract}

\section{Highlights}

- Metolachlor toxicity toward diatoms is hardly assessed with classical endpoints. Metolachlorinduced changes in the mobility of Gomphonema gracile were analyzed. Time-dose-dependent relationships were highlighted. Higher diatom velocity and movement linearity were observed with metolachlor.

Keywords : Diatoms, Physiology, Behavior, Pesticide exposure, Motility, CASA 


\section{Introduction}

Motility has been described in many pennate diatoms (e.g. Bertrand, 1999 and Harper, 1977), and migration plays a role in photoregulation, described as a major behavioral response in intertidal environments (Ni Longphuirt et al., 2006 and Serôdio et al., 2012). Freshwater diatom motility, also 
observed in response to light intensity (Cohn, 2001; Cohn et al., 2004), may be affected by environmental factors other than light (Cohn and Disparti, 1994; Cohn et al., 2003). The decrease in the speed of the diatom Craticula cuspidata has been proposed to assess toxicity of sediment elutriates (Cohn and McGuire, 2000). Ahmed and Häder (2010) demonstrated inhibition of the percentage of motile cells and of upward swimming in Euglena gracilis exposed to heavy metals. When dealing with community ecotoxicology, the motility trait is preferred to the effective behavioral descriptors in toxicity assessment, and is calculated based on the structural composition (and more specifically, growth forms) of communities and ability of some species to move (i.e. species belonging to the "motile guild", as defined by Passy, 2007). Indeed, the structure of the biofilm is made up of very diverse species, with various growth forms controlling its thickness. The layers of cells closest to the substrates are dominated by prostrate tightly attached diatoms. Other diatom growth forms (clumps, filaments) compose a complex three-dimensional structure. Species not fixed have the ability to move within the biofilm matrix. According to Roubeix et al. (2011b) or Paule et al. (2013), the abundance of potentially motile taxa is expected to increase with toxic contamination. Indeed, the motile species are assumed to be able to control their refuge within the biofilm (Larras et al., 2012), or regulate the balance between access to environmental resources (light, nutrients) and exposure stress (Fore and Grafe, 2002; Laviale et al., 2009). But, the real motility response to toxicants has been, to date, overlooked and requires experimental validation.

A toxicant entering the cell generates a dramatic accumulation of reactive oxygen species (ROS) in the cytosol (Wang et al., 2004). Excess ROS are cytotoxic and have different cellular targets (nucleus, mitochondria and chloroplasts). Adverse effects in diatoms are most often: damage to the photosynthetic apparatus (Knauert and Knauer, 2008) affecting D1 protein resulting in photoinhibition (Cartaxana et al., 2013); damage to the electron transfer chain in mitochondria, causing a decrease in ATP production (Stohs and Bagchi, 1995); damage to DNA affecting vegetative growth (Stohs and Bagchi, 1995). The way to cope with sublethal contamination would rather be linked to temporary physiological adaptation: low concentrations of toxicants promote hormesis (compensatory stimulation), as a mechanism to counteract the stress induced by the toxicant. In microalgae, an increase in chlorophyll- $a$ synthesis ("greening effect") can be observed (e.g. Tlili et al., 2011) as a short term response to maintain an efficient photosynthetic processes. In contrast, exposure to higher doses may provoke more overwhelming responses (even death). The capacity to escape may thus constitute a serious advantage for cells experiencing contamination.

Metolachlor [2-chloro-N -(2-ethyl-6-methylphenyl)-N-(2-methoxy-1-methylethyl) acetamide] is a preemergent and early post-emergent chloroacetanilide herbicide widely used in agriculture and detected at high concentrations in rivers in particular during the field application period and after rainfall (e.g. Liu and Xiong, 2009; Roubeix et al., 2012). It inhibits growth by suppressing synthesis of chlorophyll, proteins, fatty acids and lipids, isoprenoids, and flavonoids (Fuerst, 1987; Rivard, 2003). Assessing 
metolachlor toxicity is challenging, because current diatom indicators of toxic impact (mainly growth and photosynthesis) fail to properly assess metolachlor toxicity, except when it is at extremely high concentrations (Debenest et al., 2009; Roubeix et al., 2012; Roubeix et al., 2011a).

We designed a specific experiment to determine behavior changes (motility parameters) of a pennate diatom isolated in the field (Gomphonema gracile Ehrenberg) when exposed to three environmentally realistic concentrations of metolachlor. In our experiment, we hypothesized that physiology and behavior would be modified by exposure to metolachlor. More specifically, we expected the responses to preferentially be in situ resistance at low doses (increased reproduction or photosynthetic processes) and escape (increased motility) at higher concentrations. Over a certain level of exposure, and thus stress for the organisms, impacts on population dynamics (reproduction and mortality) were also expected to occur. A delay before the detection of an impact, and the potential non-linearity of the dose-response relationships, could complicate toxicity assessment. Here we aimed to determine whether motility parameters, obtained with a rapid method commonly used in animal biology (an ImageJ plug-in), would provide a finer assessment of metolachlor toxicity earlier than commonly used descriptors.

\section{Materials and methods}

\subsection{Gomphonema gracile}

Gomphonema gracile Ehrenberg (1838) is a benthic species preferentially found in slightly acidic waters (Germain, 1981). Its length and width range from 20 to $100 \mu \mathrm{m}$ and from 4 to $11 \mu \mathrm{m}$, respectively (Krammer and Lange-Bertalot, 1986). This species is considered to be very sensitive to various types of pollution (according to the Indice de Polluosensensibilité Spécifique: Coste in Cemagref, 1982). It is a pennate diatom and has a bidirectional movement, like most raphid species (Cohn, 2001).

The specimen used was from a field sample (December 2013) collected from an upstream section of the river Leyre, the main tributary of Arcachon Bay (South West France) by micromanipulation under the inverted microscope, and cultured in Dauta medium (Dauta, 1982). The culture was incubated in a chamber with a light/dark cycle of $12 \mathrm{~h}: 12 \mathrm{~h}$ at a mean temperature of $20^{\circ} \mathrm{C}$. The culture was regularly (every 1-2 weeks) transplanted into freshly prepared medium. Diatom length in our cultures was mainly in the range of $20-40 \mu \mathrm{m}$. The effective quantum yield (see Section 2.1.3) of the culture was periodically checked prior to the experiment and found to be stable over time $(0.36 \pm 0.00, n=70)$. 


\subsection{Experimental design}

Thirteen experimental units (EUs) of $40 \mathrm{~mL}$ (final volume) were filled with culture medium autoclaved at $121^{\circ} \mathrm{C}$ for 21 minutes and with the culture of G. gracile, at an initial cell concentration of around 30000 cell.mL ${ }^{-1}$. Four EUs were used as control replicates (named $\mathrm{C} 0$ ), and the three concentrations of increasing exposure $(\mathrm{C} 1, \mathrm{C} 2$ and $\mathrm{C} 3)$ were performed in triplicate. The cultures in exponential growth phase were exposed by pouring metolachlor in solution (racemic metolachlor at $100 \mathrm{mg} . \mathrm{L}^{-1}, 99.5 \%$ purity, Dr. Ehrenstorfer, Germany) into the EUs to reach the following nominal concentrations: 1,10 and $100 \mu$ g.L $L^{-1}$ (i.e. $4 \mathrm{nM}, 35 \mathrm{nM}, 352 \mathrm{nM}$ ). Three additional experimental units, used as abiotic positive controls, were filled with culture medium contaminated with the highest concentration of metolachlor. The three concentrations correspond to (i) environmentally realistic exposure concentrations $\left(1 \mu \mathrm{g} . \mathrm{L}^{-1}\right)$ in the Leyre watershed (Roubeix et al., 2012) or other rivers of the area (Fauvelle et al., 2014), and (ii) for the higher ones, concentrations of the same order of magnitude as those used in other ecotoxicological studies (Debenest et al., 2009; Roubeix et al., 2011a). The cultures were thus exposed to these four treatments over 7 days, during which samples were taken for chemical and biological measurements.

\subsection{Biological endpoints}

Biological endpoints were determined on day 0 ( $d 0$, immediately after contamination), $d 1, d 2, d 3, d 4$ and $\mathrm{d}$ 7. First, measurements of yield and chlorophyll- $a$ fluorescence were performed directly on the intact biofilms (in their benthic "form"). Then the cultures were gently shaken to homogenously suspend the cells before sampling aliquots for the other endpoints measured: $20 \mu \mathrm{L}$ were used for the motility measurements and image acquisition; $375 \mu \mathrm{L}$ were preserved with a $25 \mu \mathrm{L}$ drop of formalin solution for growth and mortality analyses; $300 \mu \mathrm{L}$ were immediately frozen for further ATP content determination.

\subsubsection{Chlorophyll-a fluorescence derived parameters.}

Measurements were performed on the intact biofilms, using a PHYTO-PAM (Heinz Walz, GmbH) equipped with an emitter-detector unit (PHYTO-EDF). Using a home-made system for reproducible direct measurements on bottom of the EUs, ten randomly selected benthic measurements of the effective quantum yield ( $\Delta \mathrm{F} / \mathrm{Fm}$ ') and chlorophyll- $a$ content estimated by chlorophyll- $a$ fluorescence (Chl-a) were performed to account for the patchy pattern of benthic settlement (especially in the initial phase of colonization). The median of 10 values per sample was then used for statistical analyses.

\subsubsection{Motility.}

The motility parameters (percentage of motile cells, velocity) were determined using the ImageJ plugin, CASA (Computer-assisted sperm analysis). This plug-in, initially developed to measure the motility of human spermatozoa, was adapted to animal biology (zebrafish sperm) by Wilson-Leedy 
and Ingermann (2007) and is commonly used to analyze the movement of trochophore larvae, sea bass spermatozoa, etc. It allows a quick measurement of different motility parameters, characterizing the general state of the cells.

The measurement conditions as well as the CASA plug-in were specifically adapted to Gomphonema gracile. Briefly, a $20 \mu \mathrm{L}$ drop of sample was carefully deposited onto a microscope slide and, after 2-3 min, video acquisition (Archimed ${ }^{\mathrm{TM}}$, Microvision Instruments) was performed. Cell motion variables, calculated from 260 frames and corresponding to $10 \mathrm{~s}$ of film, were: VAP (velocity average path), VCL (velocity curvilinear), VSL (velocity straight line) and LIN (linearity, LIN=VSL/VAP). The measurement of these parameters (automatized in the CASA plug-in) allows the characterization of the different velocity types and, for the LIN parameter, describes the curvature of the trajectory (Rurangwa et al., 2004).

\subsubsection{Population dynamics.}

The enumeration of live and dead diatoms was carried out at a x400 magnification (Olympus BX51 upright microscope, UK) using a Nageotte counting cell chamber (see Morin et al., 2010 for details). Solitary cells were also distinguished from those forming associations in the counts. Growth rates were calculated from live cell densities during the whole experiment, following Morin et al. (2008).

In diatoms, population growth is dominated by cell division, leading to a reduction in the size of the daughter cells (Round et al., 1990); larger cell sizes are only recovered after sexual reproduction. Gomphonema species are known to undergo sexual reproduction (Drebes, 1977; Rose and Cox, 2013). Thus, a shift in cell distribution towards smaller cell classes would reflect vegetative-dominated reproduction, whereas larger sizes could indicate sexual reproduction (but see Rose and Cox, 2013). Reproduction mode (vegetative vs. sexual) was assessed by measuring cell lengths ( 10 values per replicate) throughout the experiment. Length data were discretized into size classes using Huntsberger's formula (Huntsberger, 1961):

$$
1+3.32 \times \log _{10}(n), \text { where } n \text { corresponds to data numbers }
$$

An optimal number of six size classes was obtained. Size class limits were selected in order to respect homogeneity of data distributions, and interval classes of the same width were fixed. We assumed that an increase in the number of larger cells $(>34 \mu \mathrm{m})$ between two sampling dates was related to sexual reproduction.

\subsubsection{ATP content.}


The cellular ATP content was measured from $300 \mu \mathrm{L}$ of the cultures, in microwells using the PerkinElmer ATPlite ${ }^{\mathrm{TM}}$ kit according to the manufacturer's instructions. Luminescence measurements were performed with a Synergy HT multi-mode microplate reader (Biotek ${ }^{\circledR}$ ).

\subsection{Metolachlor concentrations}

One milliliter of water was collected in all EUs 30 min after contamination (d0), and on d4 and d7, for dissolved metolachlor analysis in order to assess actual exposure throughout the experiment. Samples were filtered through syringe filters in regenerated cellulose (Spartan ${ }^{\circledR} 13 \mathrm{~mm}$ diameter, pore size $0.45 \mu \mathrm{m}$, Whatman ${ }^{\circledR}$ ) and stored frozen until HPLC-ESI-MS/MS analysis (API 2000® triple quadrupole mass spectrometer, Applied Biosystems/MDS SCIEX). As the quantification limit was of $1 \mu \mathrm{g} . \mathrm{L}^{-1}$, samples from $\mathrm{C} 0$ and $\mathrm{C} 1$ were preconcentrated 5-fold (evaporation of the 1-mL sample using a RapidVap system and reconstitution of the residue in a 90/10, v/v mixture of ultrapure water and acetonitrile), and $\mathrm{C} 3$ prediluted 5-fold prior to analysis.

At the end of the experiment, the replicate Gomphonema gracile suspensions of each treatment were pooled to get enough fresh material for measurement of total metolachlor bioaccumulation. Samples filtered through GF/F filters (47 mm glass microfiber filters, pore size $0.45 \mu \mathrm{m}$, Whatman ${ }^{\circledR}$ ) were then extracted by ASE (Dionex ${ }^{\circledR}$, Accelerated Solvent Extractor 200) and stored frozen until HPLCESI-MS/MS analysis.

\subsection{Statistical analyses}

Undetectable metolachlor concentrations were replaced by half the value of the detection limit according to Helsel (1990) to determine statistical differences between exposure conditions.

Repeated-measures ANOVAs and Newman-Keuls post-hoc tests were run in Statistica 10 (StatSoft, Inc, Tulsa, OK, USA) to detect differences between samples, with a significance level of $p<0.05$. Correlated variables were identified using Multiple Factor Analysis for a mixture of qualitative and quantitative variables (MFAmix) inside the groups of endpoints (related respectively to population dynamics, physiology and behavior). MFAmix is an extension of Principal Component Analysis (PCA) handling heterogeneous (quantitative and categorical) variables. First, PCA for mixed data (PCAmix) are computed for each group of endpoints (population dynamics, physiology and behavior), using the set of quantitative and qualitative variables measured. Then, the three PCAmix are given the same weight (normalized) to remove the influence of datasets of different sizes on the final inertia. Finally, the normalized matrices are combined into a common representation of the different data. The map of observations or variables plotted reflects the similarities between the observations. The analysis was performed in the R environment, using the package PCAmixdata (Chavent et al., 2014).

\section{Results}




\subsection{Control units.}

\subsubsection{Population dynamics.}

From $\mathrm{d} 0$ to $\mathrm{d} 4$, the diatom cell density increased significantly from $31168 \pm 2538$ cell. $\mathrm{mL}^{-1}$ on $\mathrm{d} 0$ to $162389 \pm 10030$ cell. $\mathrm{mL}^{-1}$ on $\mathrm{d} 4$ (Figure 1a), with an average growth rate of $0.41 \pm 0.03$ divisions/day. Simultaneously, the percentage of dead diatoms decreased continuously from $\mathrm{d} 0(4.29 \pm 0.66 \%)$ to $\mathrm{d} 4$ $(0.09 \pm 0.07 \%)$. On $\mathrm{d} 7$, mortality increased $(0.38 \pm 0.10 \%)$ and growth rate clearly decreased $(0.31 \pm 0.03$ divisions/day between $\mathrm{d} 4$ and $\mathrm{d} 7$ ) indicating that the cultures were no longer in exponential growth.

The distribution of size classes is shown in Figure $1 \mathrm{~b}$. From $\mathrm{d} 0$ to $\mathrm{d} 2$, the proportion of the highest size (>34 $\mu \mathrm{m})$ class decreased. At the same time, the proportion of intermediate classes (32-34, 30-32 and 28-30 $\mu \mathrm{m}$ ) increased indicating that vegetative reproduction dominated. On $\mathrm{d} 3$, the proportion of highest size class increased suggesting sexual reproduction.

\subsubsection{Physiology.}

The chlorophyll- $a$ content measurements increased over the duration of the experiment (Figure 2a), following the cell growth (Figure 1a). The effective quantum yield ( $\triangle \mathrm{F} / \mathrm{Fm}$ ') of the $\mathrm{C} 0$ cultures (Figure $2 \mathrm{~b}$ ) did not change significantly during the seven days, and perfectly matched the values measured over the weeks preceding the experiment $(0.36 \pm 0.00, n=70)$. This confirms that our experimental conditions did not significantly impact yield. ATP content decreased over time (not shown).

\subsubsection{Behavior.}

The percentage of motile cells (Figure 3b) decreased in the first days of the experiment. From d3, the number of motile cells increased significantly. This temporal pattern was inversely correlated with the clumping of individuals giving small scattered aggregation patterns (Figure $3 \mathrm{a}$ ): an increase from d0 to d3 (highest percentage of cells in associations) followed by a significant decrease until d7. Motility was noted in $43 \pm 5 \%$ of the cells on $\mathrm{d} 0$ falling to $15 \pm 1 \%$ on $\mathrm{d} 3$, while larger numbers of ribbon- to starshaped associations ( $4-7$ cells in the first days, then 8-10 cells) were noted. The abundance of cell clumps peaked on $\mathrm{d} 3$ ( $20 \pm 3 \%$ of the total number of cells), then they tended to disaggregate from day 4 (smaller clumps) and/or disintegrate on $\mathrm{d} 7$, potentially indicating biofilm senescence. Conversely, the percentage of motile cells increased to $72 \pm 3 \%$ at this date, confirming population decay.

Whatever the velocity measurement considered, the values significantly increased from $\mathrm{d} 0$ to $\mathrm{d} 2$, then stabilized until d7 (Figure 3c, 3d and 3e). On d0, velocities were of 5.81 $\pm 0.17 \mu \mathrm{m} . \mathrm{s}^{-1}$ (VAP), $6.68 \pm 0.42 \mu \mathrm{m} . \mathrm{s}^{-1}$ (VCL) and 4.30 $\pm 0.26 \mu \mathrm{m} . \mathrm{s}^{-1}$ (VSL), and reached $8.50 \pm 0.20 \mu \mathrm{m} . \mathrm{s}^{-1}$ (VAP), $9.08 \pm 0.18$ $\mu \mathrm{m} . \mathrm{s}^{-1}$ (VCL) and $7.48 \pm 0.28 \mu \mathrm{m} . \mathrm{s}^{-1}(\mathrm{VSL})$ on $\mathrm{d} 2$. The LIN parameter was on average $0.86 \pm 0.02$ over 
the 7-day experiment (Figure 3f), indicating a constant trajectory (relatively linear) of the cells (illustrated in Supplementary material).

\subsubsection{Correlations between physiological, behavioral and populational descriptors.}

The two common parameters used to estimate periphytic biomass, cell density and chlorophyll- $a$ fluorescence, were well correlated $\left(\mathrm{R}^{2}=0.94, p<0.0001\right.$; also see Figure 4). Both increased with time, highlighting the exponential growth of the cultures. Growth rates were inversely correlated with average diatom length and percentage of larger cells (Figure 4), highlighting the key role of vegetative reproduction in the exponential growth. The decrease in ATP content over time, simultaneous with exponential cell growth $\left(\mathrm{R}^{2}=0.45, p<0.0001\right)$, and the negative correlation with sexual reproduction (Figure 4), also expressed culture growth and ageing.

In contrast to these unidirectional trajectories, behavioral descriptors provided complementary information about the structural evolution of the cultures under control conditions. Indeed, we observed that increasing aggregation of cells was inversely correlated with the percentage of motile cells $\left(\mathrm{R}^{2}=0.46, p<0.0001\right)$. The velocity parameters (VAP, VCL and VSL) were well correlated, with a positive relationship between VAP and VCL $\left(\mathrm{R}^{2}=0.93, \mathrm{p}<0.0001\right)$, as well as with VSL due to the constant linearity value of the trajectories over time (LIN=VSL/VAP).

3.2. Metolachlor-contaminated units

\subsubsection{Chemical concentrations}

Metolachlor concentrations measured in the EUs containing G. gracile were close to the nominal concentrations: the anticipated gradient of exposure of our cultures was respected (Figure 5).

Concentrations were below quantification limits in C0, and 1.1 $\pm 0.2 \mu \mathrm{g} . \mathrm{L}^{-1}$ in $\mathrm{C} 1,9.1 \pm 0.5 \mu \mathrm{g} . \mathrm{L}^{-1}$ in C2 and $45.5 \pm 6.6 \mu \mathrm{g} . \mathrm{L}^{-1}$ in $\mathrm{C} 3$ over the 7-day experiment. Metolachlor concentrations in the abiotic EUs (highest concentration) on $\mathrm{d} 0$ and $\mathrm{d} 7 \mathrm{did}$ not differ from those measured in $\mathrm{C} 3$ at the same sampling dates (Figure 5). Concentrations decreased slightly over time in all treatments (although this was not statistically significant).

Final biomass collected on the filters for bioaccumulation measurements was quite high (18 $2 \mathrm{mg}$ lyophilized weight), but no metolachlor was quantified in the biota, even at the highest concentration (C3).

\subsubsection{Population dynamics.}

Exponential growth was globally similar between controls and treatments (Figure 1a) from $\mathrm{d} 0$ to $\mathrm{d} 4$. On $\mathrm{d} 7$, however, diatom cell numbers were significantly lower at the highest exposure concentrations than in the controls (Figure 1a), with densities of $338660 \pm 21950$ cells.mL ${ }^{-1}$ in $\mathrm{C} 2$ and 
$349468 \pm 24389$ cells.mL ${ }^{-1}$ in C3 (compared to $411563 \pm 26394$ cells.mL ${ }^{-1}$ in the controls). The distribution of size classes in $\mathrm{C} 1$ and $\mathrm{C} 2$ treatment was similar to that of the controls (Figure 1b). Sexual reproduction (recovery of larger cell sizes) was however delayed with highest exposure (in C3), happening 1-2 days later than with the other treatments.

\subsubsection{Physiology}

Chl- $a$ increased over time in all EUs (Figure 2a), but was significantly inhibited at high doses (in C3 on d7), whereas a slight stimulation of fluorescence was observable earlier (d1, d3) at lower doses. The effective quantum yield ( $\Delta \mathrm{F} / \mathrm{Fm}$ ') did not differ significantly from the controls, whatever the exposure concentration (Figure $2 \mathrm{~b}$ ). ATP production was not significantly impaired by the concentrations of metolachlor used and was not different from that of the controls (not shown), suggesting that overall metabolism was maintained.

\subsubsection{Behavior.}

A significant increase in the percentage of motile cells with metolachlor exposure was measured on $\mathrm{d} 3$ (Figure 3a). Motility was significantly higher for all treatments $(60 \pm 11 \%)$ compared to the controls. At the same sampling date, cell associations were also impacted (Figure $3 \mathrm{~b}$ ): on $\mathrm{d} 3$ cells grew in less aggregated patterns than in the controls, especially for $\mathrm{C} 3$ where the percentage of diatoms forming associations was always lower than in $\mathrm{C} 0$.

The VAP and VCL were still well correlated $\left(\mathrm{R}^{2}=0.96, \mathrm{p}<0.0001\right.$ for the contaminated EUs; Figure 4) and no significant effect of metolachlor was observed on these parameters (Figures $3 \mathrm{c}$ and $3 \mathrm{~d}$ ). Conversely, the VSL of motile diatoms tended to increase with time, and was significantly higher in $\mathrm{C} 2$ from d4 (Figure 3e). The LIN parameter increased slightly in C2 from day 4, and significantly higher LIN was measured on day 7 in all treatments compared to $\mathrm{C} 0$, indicating a more linear, although jerkier movement (observation not quantified). Linearity particularly increased in $\mathrm{C} 2$ at the last date (Figure $3 \mathrm{f}$ ).

\subsubsection{Correlations between physiological, behavioral and populational descriptors.}

Figure 4 provides an overview of the correlations between physiological, behavioral and populational descriptors in this experiment. Cell densities and Chl- $a$ were still well correlated $\left(\mathrm{R}^{2}=0.89\right.$, $p<0.0001$ ), although some discrepancies were observed in comparison to the controls: chlorophyll- $a$ fluorescence was enhanced at lower doses, and decreased with the highest concentration of exposure at the end of the experiment. Metolachlor effects were mostly highlighted by motility parameters, driving correlations (see Figure 4, top-right corner) between higher percentages of motile cells and a more linear trajectory $(p<0.0001)$. 


\section{Discussion}

In ecotoxicology studies, the parameters commonly used to assess the impact of a molecule on microalgae are generally growth and photosynthesis, because of rapidity and ease of measurement. Based on the sole use of these two endpoints, toxicity can be underestimated, especially in the case of toxicants not directly targeting photosynthesis. This may explain the high effective concentrations $\left(\mathrm{EC}_{50} \mathrm{~s}\right)$ of metolachlor (inhibitor of fatty acid and lipid synthesis; Fuerst, 1987) found in the literature. Toxicity values based on photosynthesis and growth are of the order of milligrams per liter (Juneau et al., 2001; Ma et al., 2006; Thakkar et al., 2013). There is an urgent need to develop complementary toxicity endpoints. This work is thus topical, as the use of motility endpoints provides an image of the general state of cells, assessing toxicity on (an)other metabolic target(s). Moreover, it is quickly and easily quantifiable. Motility is characterized via the quantification of different parameters (velocity values: VAP, VCL, VSL; linearity; percentage of motile cells). For approximately 40 years (Rupert and Dagmar, 2014), motility has been commonly used in animal biology as a quality indicator of human sperm, and as an endpoint of toxicity. More recently, motility endpoints were successfully used with for example fish and bivalve sperm, trochophore larvae, thanks to the CASA system (WilsonLeedy and Ingermann, 2007). Wilson-Leedy and Ingermann made this method of motility assessment more accessible, by developing an easy-to-use plug-in implemented in the freeware ImageJ. In the present study, we aimed to demonstrate its applicability to algae, and to determine the motility parameters of Gomphonema gracile, a diatom chosen because of its high sensitivity to pollutants and its presence in the environment studied, the Leyre river.

\subsection{Control conditions}

Under control conditions, the five motility parameters assessed showed different patterns of change during the experiment. Indeed, the VAP, VSL and VCL velocities increased the first days (d0 to d2) then stagnated. In contrast, the LIN parameter describing the cell trajectory directly, did not depend on the age of the culture. Changes in motility were consistent with other parameters related to population dynamics (growth rate, class size distribution), physiology (chlorophyll- $a$ content, effective quantum yield, ATP content) and behavior (percentage of cells in association). Indeed, our results indicated an increase in cell velocity (VAP, VSL and VCL) in the first three days, corresponding with decreasing ATP content (Figure 4), thus revealing higher energy consumption for motility purposes (e.g. see Bertrand, 1999). Besides, the initial decrease (from d0 to d3) in the percentage of motile cells showed that exponential growth during the first days of the experiment coincided with the formation of diatom associations (Vieira et al., 2008), as a consequence of the natural development of Gomphonema gracile populations. Gomphonema gracile cells were mainly solitary, as expected for highly motile 
species (Hudon and Legendre, 1987). On the first days, clusters started to form in the culture, with increasing aggregation of cells. In another study performed with shaken cultures of Nitzschia angularis and Thalassiosira weissflogii, Crocker and Passow (1995) also observed cell aggregates within 6 hours. As cells aggregated, lower numbers of motile individuals were predictably found. Population density and cell proximity increased the likelihood of sexual reproduction (Mann, 2011), and the cell aggregations observed may have favored sexuality, as observed through the recovery of larger cell sizes in the 2-3 first days. Then Gomphonema associations tended to disaggregate from day 4 (smaller clumps) and/or started to senesce on d7, with aging of the populations. At the same time, increasing numbers of motile diatoms were recorded. Decreased cell aggregation in the stationary growth phase was also suggested by Decho (1990). The kinetics of cell clustering depend on the species considered (Crocker and Passow, 1995), but discernable patterns were observed in our Gomphonema cultures. The cells quite quickly formed loose aggregates during their first stage of exponential growth, which then became denser. Aggregation is involved in diatom sinking, and here it may have contributed to forming the benthic mats observed on the bottoms of the EUs. Then, with population senescence and/or crowding, the search for more favorable conditions would be allowed by disaggregation and increased motility.

\subsection{Diatom responses to metolachlor exposure}

Besides the validation of the motility evaluation method, this study aimed to characterize the toxicity of metolachlor on a whole set of parameters and to demonstrate the interest of increasing the number of endpoints, in order to properly assess the toxicity of any type of molecule with various modes of action, in particular those not targeting photosynthesis directly.

\subsubsection{Metolachlor exposure.}

Although metolachlor concentrations in the EUs clearly fitted a gradient, the highest dose prepared only reached half its nominal concentration. Several hypotheses may explain this loss of dissolved metolachlor, including: bioaccumulation in the diatom cells, degradation and adsorption on the UE walls. The first two were refuted by the analysis of diatom biomass (no metolachlor detected) and in the water of the abiotic EUs (no breakdown products quantified, data not shown). Moreover, dissolved metolachlor concentrations were similar in $\mathrm{C} 3$ (i.e. with diatom cultures) and in the abiotic EUs, supporting the hypothesis of rapid adsorption onto the EU walls (within the 30 first minutes).

Even at the highest concentration, no metolachlor was quantified in biofilms, tending to disprove the conclusion of Larras et al. (2013) that hydrophobicity of substances alone can be used to predict benthic diatom exposure through bioaccumulation. Indeed, their statement was based i) on the relationships obtained in biofilms by Headley et al. (1998) between short-term sorption capacity of organic contaminants and their hydrophobicity, and ii) on their experimental results highlighting 
greater sensitivity towards hydrophobic substances (irgarol, metolachlor, terbutryn) of benthic diatoms, compared to planktonic forms. They came to the conclusion that this sensitivity should be explained by sorption in the biofilm matrix (Larras et al., 2013). In the case of metolachlor, our results demonstrate that low bioaccumulation is to be expected, and that sorption processes are determined by properties other than hydrophobicity of the compound. Here, exposure, and subsequent toxicity, relied more on dissolved metolachlor concentrations.

\subsubsection{Time-dose dependent impacts on diatoms.}

As expected, very few endpoints highlighted metolachlor effects on population growth and physiology. Indeed, there was no significantly diverging trend over the experiment in most of these parameters, except for chlorophyll- $a$ fluorescence, and a slight (although above the $5 \% \alpha$-level) impact on cell association. ATP production was not significantly impaired by the concentrations of metolachlor used (not shown), suggesting that overall metabolism was maintained. Growth and effective quantum yield were globally similar between controls and treatments (Figure 1a, 2b), as were VAP and VCL (Figure 3c-d). However, certain parameters were affected by metolachlor exposure. A time effect was almost always observed, and the impact of treatment was visible only at certain times of exposure, suggesting that population responses did not follow unidirectional trajectories but rather followed time-dependent patterns, with possible successive shifts in strategies.

The effects on chlorophyll- $a$ content were clearly dose-dependent: a slight stimulation of fluorescence was observable at low doses, whereas it was significantly inhibited at the highest concentration (Figure 2a). These results stress that coping with sublethal contaminations requires optimal allocation of energy to specific processes, to counterbalance the impacts of the toxicants. This phenomenon is known as hormesis (Calabrese, 2005). Biofilm stimulation of chlorophyll fluorescence has been shown to occur broadly with low dose exposure (e.g. Ricart et al., 2009; Tlili et al., 2011; Tlili et al., 2008), for diverse classes of chemicals. This consistent compensatory response suggests that extra allocation of resources to fluorescence may be sufficient to maintain photosynthetic activity, without affecting the total number of cells, in slightly impacted environments. Indeed, the cultures displayed dose-time dependent hormetic responses: the "greening effect" was recorded earlier in $\mathrm{C} 1$ (d1, d3) than $\mathrm{C} 2$ (on d4). Fluorescence stimulation in $\mathrm{C} 1$ and $\mathrm{C} 2$ suggested that diatoms were able to implement the same tolerance mechanisms, at timescales depending on the intensity of the stress. As time progressed, fluorescence levels returned to control values. In contrast, the inhibition on the last days of experiment in $\mathrm{C} 3$ indicated deleterious impacts for the culture, converging with the conclusions of Debenest et al. (2009) that diatoms are sensitive to chronic metolachlor exposure from $30 \mu \mathrm{g} . \mathrm{L}^{-1}$.

The highest concentration (C3) of exposure impacted the size class distribution, the percentage of cells in associations and the percentage of motile cells on day 3. Other works have also demonstrated that 
toxicants can effect the distribution of cell sizes in diatom populations (decrease in average cell size with metal exposure; Luís et al., 2011) and particularly delayed sexual reproduction (later recovery of larger cell sizes). The percentage of cells forming associations was lower in the treatments than in the controls (Figure 3a), suggesting that toxicant exposure may also affect the normal structure of the biofilm. Previous works showed that pesticides, including chloroacetanilides, modify the 3-D structure of more complex (multispecies) biofilms by reducing biofilm thickness and the distribution of the life forms present (e.g. Roubeix et al., 2012; Roubeix et al., 2011a regarding metolachlor). The lower numbers of aggregated cells in $\mathrm{C} 3$ indicated that changes could also occur at the population level, contributing to alterations in the overall biofilm architecture. Despite the fact that association in colonies could help the diatoms limit the influence of toxicants, by reducing the cell surface exposed or thanks to the concomitant increase in exopolymeric substance production (Crocker and Passow, 1995), cell aggregation is likely to make each cell lose its motility, thus its potential to escape the contaminant. Here, it can be noted that, contrary to the observations made by Cohn and McGuire (2000) or Ahmed and Häder (2010), the percentage of motile cells did not decrease, nor increase, with metolachlor exposure, meaning that only a given proportion of individuals within the population would be able to escape a contaminant.

Finally, the VSL velocity and the LIN parameter were found to be the most sensitive. Indeed, VSL tended to increase with time, and was higher in C2 from d4 (Figure 3e). Cell trajectory was still curvilinear in metolachlor-exposed EUs, but on $\mathrm{d} 7$ all treatments had significantly higher LIN than C0 indicating a more linear movement which could enable the diatoms to cover larger distances. Motile pennate diatoms thus regulated their motility depending on exposure to metolachlor, with higher velocity and lower trajectory curvature. Active gliding in diatoms is related to the cell's ability to secrete extracellular polymeric substances (Cohn, 2001). On the other hand, excretion of polymeric substances is also involved in resistance mechanisms: by binding the toxicant extracellularly, they contribute to limiting the entrance into the cells and thus lessen toxicity (Pereira et al., 2011). Higher motility (increased VSL and a more linear trajectory) in the metolachlor-exposed EUs with respect to controls could thus highlight both increased escape behavior against toxicants and higher excretion induced by exposure. Escape behavior could be controlled by the ROS generated by the toxicant in the cell. Indeed, Laviale et al. (2011) recently suggested ROS-controlled migration in marine diatoms, i.e. ROS acting as signaling molecules to generate movement.

\section{Conclusions and perspectives}

The cost of coping with toxicants for the organisms may not always be highlighted by the effect descriptors used so far. In microalgal ecotoxicological studies, fluorescence measurements are widely used, given the fact that most of the toxicants target any of the components of the photosynthetic chain, directly or indirectly. 
However, harmful impacts on fluorescence and to a lesser extent on cell density were observable here only at the highest concentration tested and at the end of the experiment, whereas other endpoints responded earlier and/or at lower concentrations, such as motility-related ones. The results of our experiments showed that, at low-dose exposure, energy was allocated to resist in situ (increased fluorescence), whereas increased motility at higher doses tended to indicate an escape behavior.

The generalizability of these behavioral responses should now be confirmed for diverse contaminants (with different modes of action). Motility endpoints would provide valuable perspectives for the assessment of pollutant impacts not targeting photosynthesis directly, given the fact that the use photosynthesis inhibitors is increasingly restricted (European Commission, 2012), calling for new reliable toxicity indicators other than photosynthesis-based ones.

Diatom motility, and more generally behavior, in response to perturbations has been overlooked in freshwater environments. Here, we demonstrate the relevance of this kind of response, even if further investigations are still needed for a better assessment of the value of diatom behavioral measurements. The species considered may obviously be a major source of variability, as well as its origin. Moreover, the extrapolation of these motility measurements will also require determining the degree of correlation between laboratory observations and behavior in the field.

\section{Acknowledgements}

N.C. thanks Marc Suquet for explaining the movement measuring technique in microalgae. Samuel Brown is acknowledged for proofreading the manuscript.

This study has been carried out with financial support from the French National Research Agency (ANR) in the frame of the Investments for the future Programme, within the Cluster of Excellence COTE (ANR-10-LABX-45).

\section{References}

Ahmed, H., Häder, D.-P., 2010. Rapid ecotoxicological bioassay of nickel and cadmium using motility and photosynthetic parameters of Euglena gracilis. Environmental and Experimental Botany 69, 6875 .

Bertrand, J., 1999. Mouvements des diatomées VI. Les efforts pendant le déplacement apical. Mesures, analyses, relations : longueur, vitesse, force. Cryptog. Algol. 20, 43-57.

Calabrese, E.J., 2005. Paradigm lost, paradigm found: The re-emergence of hormesis as a fundamental dose response model in the toxicological sciences. Environ. Pollut. 138, 378-411. 
Cartaxana, P., Domingues, N., Cruz, S., Jesus, B., Laviale, M., Serôdio, J., Marques da Silva, J., 2013. Photoinhibition in benthic diatom assemblages under light stress. Aquat. Microb. Ecol. 70, 87-92.

Cemagref, 1982. Study of the biologial methods for the quantitative assessment of water quality (in French). Rapport Q.E. Lyon A.F. - Bassin Rhône-Méditerranée-Corse, p. 218.

Chavent, M., Kuentz, V., Labenne, A., Liquet, B., Saracco, J., 2014. Multivariate analysis for a mixture of quantitative and qualitative data. $\mathrm{R}$ package version 2.1, http://cran.rproject.org/web/packages/PCAmixdata.

Cohn, S.A., 2001. Photo-stimulated effects on diatom motility, Photomovement. Häder, D.-P. \& M. Lebert, Elsevier Science B.V., pp. 375-401.

Cohn, S.A., Bahena, M., Davis, J., Ragland, R.L., Rauschenberg, C., Smith, B., 2004. Characterisation of the diatom photophobic response to high irradiance. Diat. Res. 19, 167-179.

Cohn, S.A., Disparti, N.C., 1994. Environmental factors influencing diatom cell motility. J. Phycol. 30, 818-828.

Cohn, S.A., Farrell, J.F., Munro, J.D., Ragland, R.L., Weitzell, R.E., Wibisono, B.L., 2003. The effect of temperature and mixed species composition on diatom motility and adhesion. Diat. Res. 18, 225243.

Cohn, S.A., McGuire, J.R., 2000. Using diatom motility as an indicator of environmental stress: effects of toxic sediment elutriates. Diat. Res. 15, 19-29.

Crocker, K.M., Passow, U., 1995. Differential aggregation of diatoms Mar. Ecol. Prog. Ser. 117, 249257.

Dauta, A., 1982. Conditions de développement du phytoplancton. Etude comparative du comportement de huit espèces en culture. I. Détermination des paramètres de croissance en fonction de la lumière et de la température. Annales de Limnologie 18, 217-262.

Debenest, T., Pinelli, E., Coste, M., Silvestre, J., Mazzella, N., Madigou, C., Delmas, F., 2009. Sensitivity of freshwater periphytic diatoms to agricultural herbicides. Aquat. Toxicol. 93, 11-17.

Decho, A.W., 1990. Microbial exopolymer secretions in ocean environments: their role(s) in food webs and marine processes. Oceanography and Marine Biology: An Annual Review 28, 73-153.

Drebes, G., 1977. Sexuality, in: Werner, D. (Ed.), The Biology of Diatoms. Bot. Monogr. 13. Blackwell Sci. Publ., Oxford., pp. 250-283.

European Commission, 2012. Priority substances under the Water Framework Directive.

Fauvelle, V., Mazzella, N., Morin, S., Moreira, S., Delest, B., Budzinski, H., 2014. Hydrophilic interaction liquid chromatography coupled with tandem mass spectrometry for acidic herbicides and metabolites analysis in fresh water. Environ. Sci. Pollut. Res. in press.

Fore, L.S., Grafe, C., 2002. Using diatoms to assess the biological condition of large rivers in Idaho (U.S.A.). Freshwat. Biol. 47, 2015-2037.

Fuerst, E.P., 1987. Understanding the Mode of Action of the Chloroacetamide and Thiocarbamate Herbicides. Weed Technology 1, 270-277.

Germain, H., 1981. Flore des diatomées. Société Nouvelle des Editions Boubée.

Harper, M.A., 1977. Movements., The Biology of Diatoms. Bot. Monogr. 13. Blackwell Sci. Publ., Oxford., pp. 224-249. 
Headley, J.V., Gandrass, J., Kuballa, J., Peru, K.M., Gong, Y., 1998. Rates of sorption and partitioning of contaminants in river biofilm. Environ. Sci. Technol. 32, 3968-3973.

Helsel, D.R., 1990. Less than obvious - statistical treatment of data below the detection limit. Environ. Sci. Technol. 24, 1766-1774.

Hudon, C., Legendre, P., 1987. The ecological implications of growth forms in epibenthic diatoms. J. Phycol. 23, 434-441.

Huntsberger, D.V., 1961. Elements of Statistical Inference, Boston.

Juneau, P., Dewez, D., Matsui, S., Kim, S.G., Popovic, R., 2001. Evaluation of different algal species sensitivity to mercury and metolachlor by PAM-fluorometry. Chemosphere 45, 589-598.

Knauert, S., Knauer, K., 2008. The role of reactive oxygen species in copper toxicity to two freshwater green algae. J. Phycol. 44, 311-319.

Krammer, K., Lange-Bertalot, H., 1986. Bacillariophyceae. 1. Teil: Naviculaceae, In Ettl, H., Gerloff, J., Heynig, H. and Mollenhauer, D. (eds) Süsswasser flora von Mitteleuropa, Band 2/1. Gustav Fischer Verlag: Stuttgart, New York, 876pp. .

Larras, F., Bouchez, A., Rimet, F., Montuelle, B., 2012. Using bioassays and Species Sensitivity Distributions to assess herbicide toxicity towards benthic diatoms. PLoS ONE 7, e44458.

Larras, F., Montuelle, B., Bouchez, A., 2013. Assessment of toxicity thresholds in aquatic environments: Does benthic growth of diatoms affect their exposure and sensitivity to herbicides? Sci. Total Environ. 463-464, 469-477.

Laviale, M., Ezequiel, J., Serôdio, J., 2011. Réponse comportementale du microphytobenthos à une variation de l'éclairement: mise en évidence expériementale de la migration, in: Lesniak, C., Ector, L., Artigas, L.F., Courcot, L., Michel, M., Prygiel, J. (Eds.), 30ème Colloque de l'ADLaF, Boulogne-surMer, p. p39.

Laviale, M., Prygiel, J., Lemoine, Y., Courseaux, A., Créach, A., 2009. Stream periphyton photoacclimation response in field conditions: Effect of community development and seasonal changes. J. Phycol. 45, 1072-1082.

Liu, H., Xiong, M., 2009. Comparative toxicity of racemic metolachlor and S-metolachlor to Chlorella pyrenoidosa. Aquatic Toxicology 93, 100-106.

Luís, A.T., Teixeira, P., Almeida, S.F.P., Matos, J.X., da Silva, E.F., 2011. Environmental impact of mining activities in the Lousal area (Portugal): Chemical and diatom characterization of metalcontaminated stream sediments and surface water of Corona stream. Sci. Total Environ. 409, 43124325 .

Ma, J., Wang, S., Wang, P., Ma, L., Chen, X., Xu, R., 2006. Toxicity assessment of 40 herbicides to the green alga Raphidocelis subcapitata. Ecotoxicology and Environmental Safety 63, 456-462.

Mann, D.G., 2011. Size and sex, in: Seckbach, J., Kociolek, J.P. (Eds.), The diatom world. Springer Science, pp. 145-166.

Morin, S., Coste, M., Delmas, F., 2008. A comparison of specific growth rates of periphytic diatoms of varying cell size under laboratory and field conditions. Hydrobiologia 614, 285-297.

Morin, S., Proia, L., Ricart, M., Bonnineau, C., Geiszinger, A., Ricciardi, F., Guasch, H., Romaní, A., Sabater, S., 2010. Effects of a bactericide on the structure and survival of benthic diatom communities. Vie Milieu 60, 109-116. 
Ni Longphuirt, S., Leynaert, A., Guarini, J.-M., Chauvaud, L., Claquin, P., Herlory, O., Amice, E., Huonnic, P., Ragueneau, O., 2006. Discovery of microphytobenthos migration in the subtidal zone. Mar. Ecol. Prog. Ser. 328, 143-154.

Passy, S.I., 2007. Diatom ecological guilds display distinct and predictable behavior along nutrient and disturbance gradients in running waters. Aquat. Bot. 86, 171-178.

Paule, A., Roubeix, V., Lauga, B., Duran, R., Delmas, F., Paul, E., Rols, J.L., 2013. Changes in tolerance to herbicide toxicity throughout development stages of phototrophic biofilms. Aquat. Toxicol. 144-145, 310-321.

Pereira, S., Micheletti, E., Zille, A., Santos, A., Moradas-Ferreira, P., Tamagnini, P., De Philippis, R., 2011. Using extracellular polymeric substances (EPS)-producing cyanobacteria for the bioremediation of heavy metals: do cations compete for the EPS functional groups and also accumulate inside the cell? Microbiology 157, 451-458.

Ricart, M., Barceló, D., Geiszinger, A., Guasch, H., Alda, M.L.d., Romaní, A.M., Vidal, G., Villagrasa, M., Sabater, S., 2009. Effects of low concentrations of the phenylurea herbicide diuron on biofilm algae and bacteria. Chemosphere 76, 1392-1401.

Rivard, L., 2003. Environmental fate of metolachlor Environmental Monitoring Branch, Department of Pesticide Regulation, Califomia, p. 14.

Rose, D.T., Cox, E.J., 2013. Some diatom species do not show a gradual decrease in cell size as they reproduce. Fundamental and Applied Limnology 182, 117-122.

Roubeix, V., Fauvelle, V., Tison-Rosebery, J., Mazzella, N., Coste, M., Delmas, F., 2012. Assessing the impact of chloroacetanilide herbicides and their metabolites on periphyton in the Leyre River (SW France) via short term growth inhibition tests on autochthonous diatoms. J. Environ. Monit. 14, 16551663.

Roubeix, V., Mazzella, N., Méchin, B., Coste, M., Delmas, F., 2011a. Impact of the herbicide metolachlor on river periphytic diatoms: experimental comparison of descriptors at different biological organization levels. Annls Limnol. (Int. J. Limnol.) 47, 1-11.

Roubeix, V., Mazzella, N., Schouler, L., Fauvelle, V., Morin, S., Coste, M., Delmas, F., Margoum, C., 2011b. Variations of periphytic diatom sensitivity to the herbicide diuron and relation to species distribution in a contamination gradient: implications for biomonitoring. J. Environ. Monit. 13, 17681774.

Round, F.E., Crawford, R.M., Mann, D.G., 1990. The Diatoms. Biology \& morphology of the genera. Cambridge Univ.Press Ed.

Rupert, P.A., Dagmar, W., 2014. Computer-assisted sperm analysis (CASA): Capabilities and potential developments. Theriogenology 81, 5-17.

Rurangwa, E., Kime, D.E., Ollevier, F., Nash, J.P., 2004. The measurement of sperm motility and factors affecting sperm quality in cultured fish. Aquaculture 234, 1-28.

Serôdio, J., Ezequiel, J., Barnett, A., Mouget, J.L., Méléder, V., Laviale, M., Lavaud, J., 2012. Efficiency of photoprotection in microphytobenthos: role of vertical migration and the xanthophyll cycle against photoinhibition. Aquat. Microb. Ecol. 67, 161-175.

Stohs, S.J., Bagchi, D., 1995. Oxidative mechanisms in the toxicity of metal ions. Free Radical Biology and Medicine 18, 321-336.

Thakkar, M., Randhawa, V., Wei, L., 2013. Comparative responses of two species of marine phytoplankton to metolachlor exposure. Aquatic Toxicology 126, 198-206. 
Tlili, A., Corcoll, N., Bonet, B., Morin, S., Montuelle, B., Bérard, A., Guasch, H., 2011. In situ spatiotemporal changes in pollution-induced community tolerance to zinc in autotrophic and heterotrophic biofilm communities. Ecotoxicology 20, 1823-1839.

Tlili, A., Dorigo, U., Montuelle, B., Margoum, C., Carluer, N., Gouy, V., Bouchez, A., Berard, A., 2008. Responses of chronically contaminated biofilms to short pulses of diuron. An experimental study simulating flooding events in a small river. Aquat. Toxicol. 87, 252-263.

Vieira, A.A.H., Ortolano, P.I.C., Giroldo, D., Oliveira, M.J.D., Bittar, T.B., Lombardi, A.T., Sartori, A.L., Paulsen, B.S., 2008. Role of hydrophobic extracellular polysaccharide of Aulacoseira granulata (Bacillariophyceae) on aggregate formation in a turbulent and hypereutrophic reservoir. Limnol. Oceanogr. 53, 1887-1899.

Wang, Y., Fang, J., Leonard, S.S., Krishna Rao, K.M., 2004. Cadmium inhibits the electron transfer chain and induces Reactive Oxygen Species. Free Radical Biology and Medicine 36, 1434-1443.

Wilson-Leedy, J.G., Ingermann, R.L., 2007. Development of a novel CASA system based on open source software for characterization of zebrafish sperm motility parameters. Theriogenology 67, 661672. 


\section{Figure captions}

Figure 1: a) Diatom live cell density, b) distribution of cell size classes (error bars not provided for clarity; statistical groups refer to differences in the largest class size: $>34 \mu \mathrm{m})$ versus time as a function of metolachlor exposure (values are mean \pm standard error, $n=4$ for controls and $n=3$ replicates for each metolachlor concentration). White bars represent $\mathrm{C} 0$, light grey bars: $\mathrm{C} 1$, dark grey bars: $\mathrm{C} 2$ and black bars: C3. Different letters indicate between-treatment post hoc differences.

Figure 2: Chlorophyll- $a$ fluorescence derived parameters versus time and as a function of metolachlor exposure (values are mean \pm standard error, $n=4$ for controls and $n=3$ replicates for each metolachlor concentration): a) chlorophyll- $a$ fluorescence, b) effective quantum yield. Bar colors are the same as in Figure 1. Different letters indicate between-treatment post hoc differences.

Figure 3: Behavioral endpoints versus time for different metolachlor exposure levels (values are mean \pm standard error, $n=4$ for controls and $n=3$ replicates for each metolachlor concentration): a) percentage of cells in associations, b) percentage of motile cells, c) average path velocity, c) curvilinear velocity, d) straight line velocity and e) linearity. Bar colors are the same as in Figure 1. Different letters indicate between-treatment post hoc differences.

Figure 4: Correlation circle of variables analyzed by Multiple Factor Analysis for quantitative and qualitative data, performed for all samples. Variables related to physiology: Chlorophyll fluorescence (Chl- $a$ ), effective photosynthetic yield ( $\Delta \mathrm{F} / \mathrm{Fm}$ ') and ATP content (ATP); to behavior: percentage of cells in associations (\% Associations) and of motile cells (\% Motile), and motility parameters (VAP, VCL, VSL, LIN); to population dynamics: diatom live cell density (Density), mean cell length (Length), percentage of cells longer than $34 \mu \mathrm{m}$ (\% Larger), growth rate (GR) and presence or absence of sexual reproduction (Reproduction).

Figure 5: Exposure in the EUs: Mean ( \pm standard error) metolachlor concentrations analyzed over the experiment ( $\mathrm{n}=4$ for controls and $\mathrm{n}=3$ for each metolachlor concentration). White bars represent $\mathrm{C} 0$, light grey bars: C1, dark grey bars: C2, black bars: C3, and dashed bars: abiotic EUs. bdl: below detection limit; nm: not measured. 
a)

(

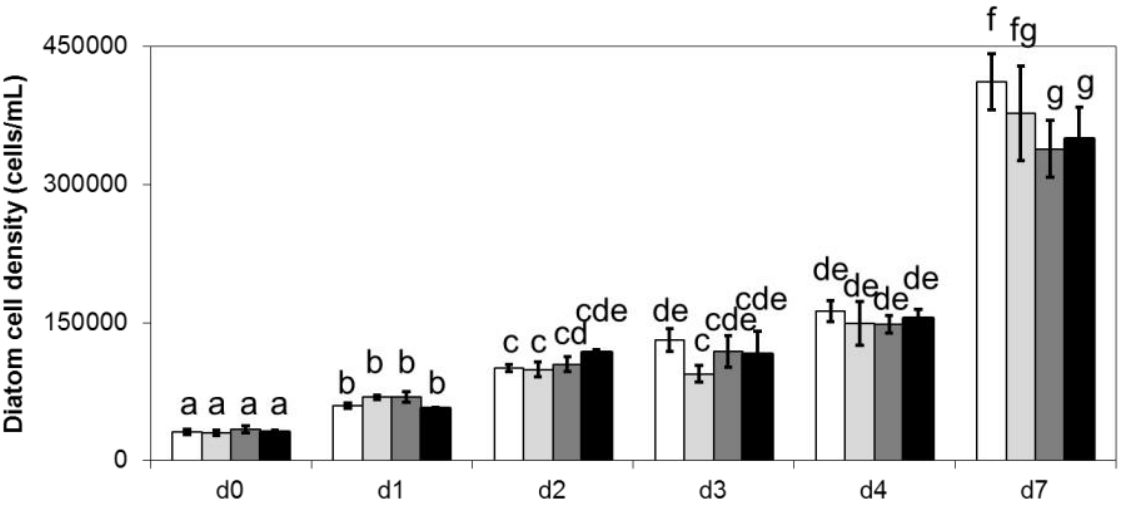

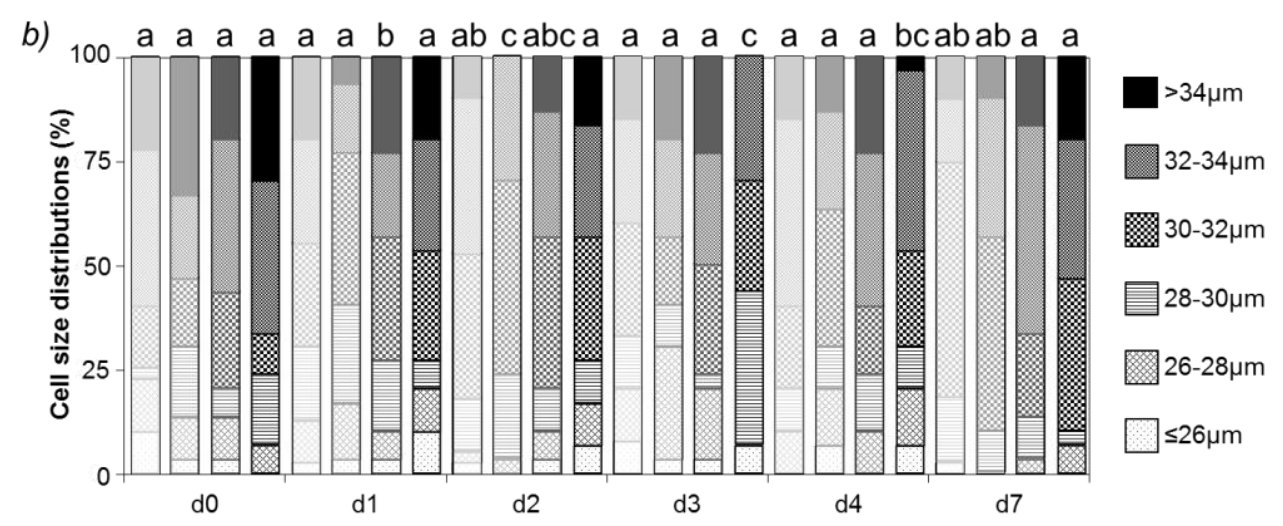

Figure 1 

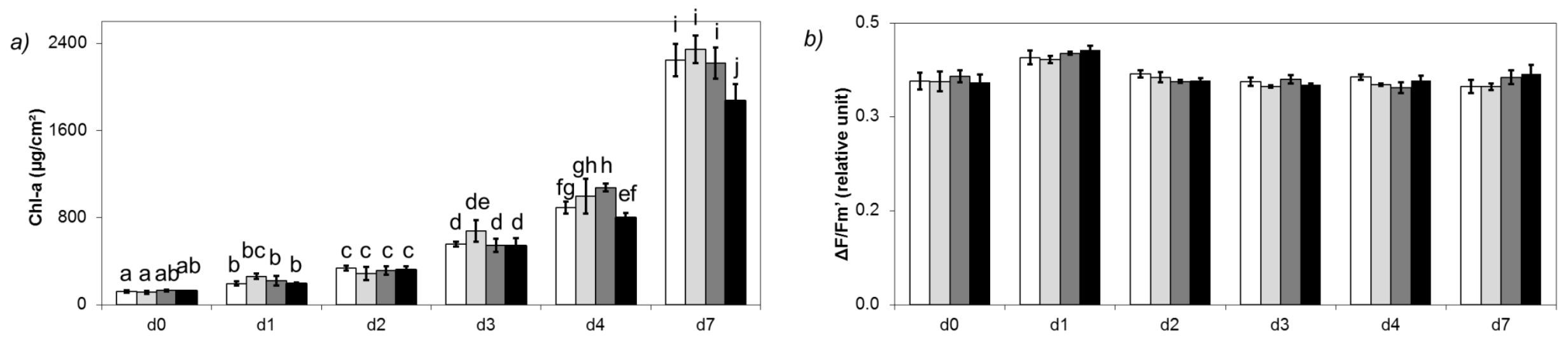

Figure 2 

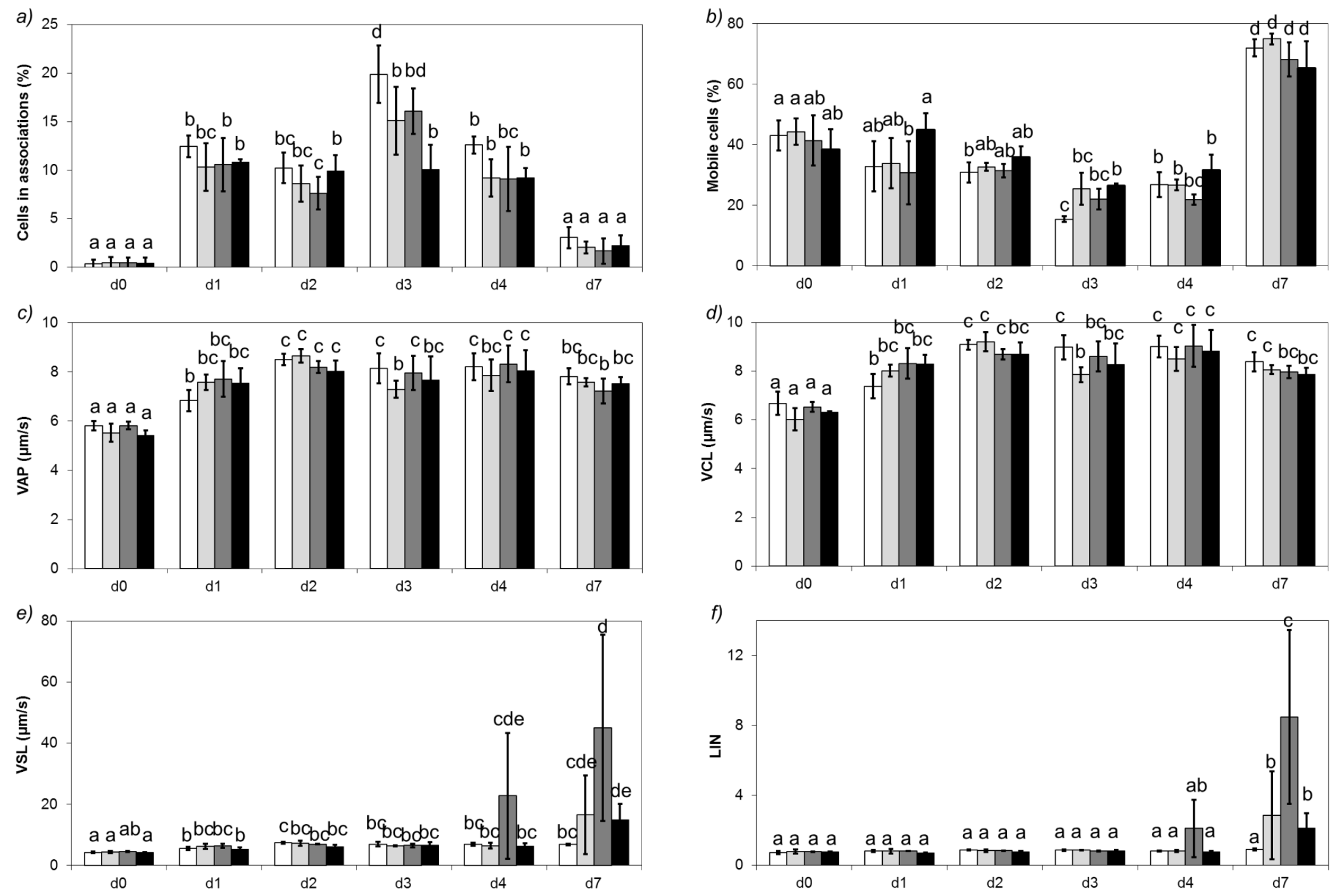

Figure 3 


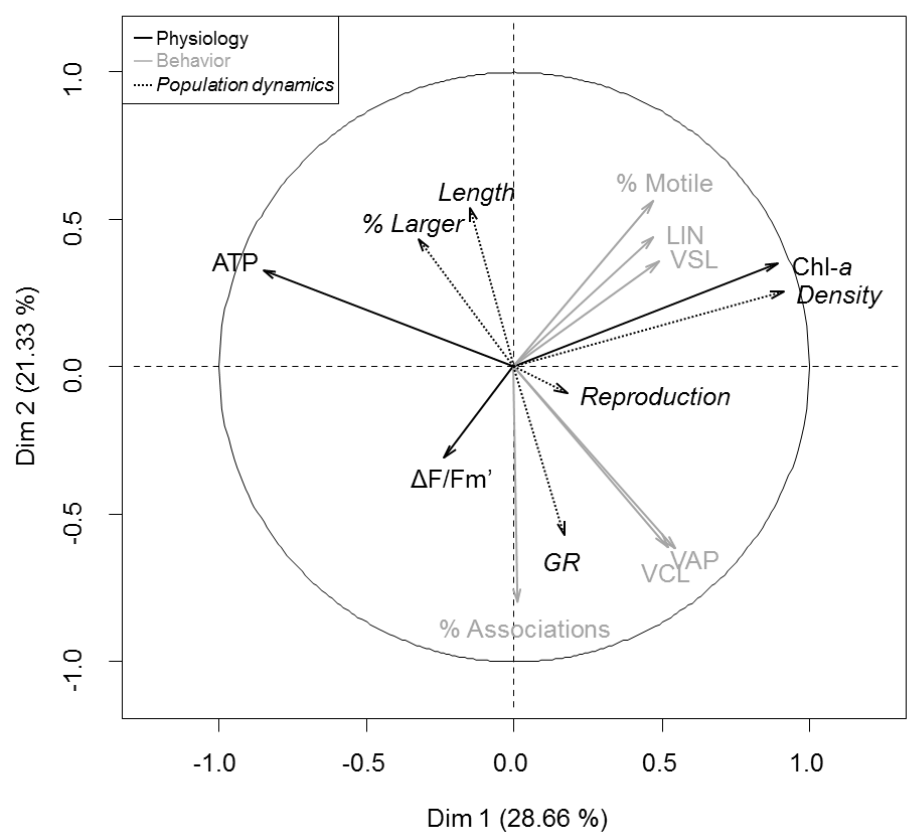

Figure 4

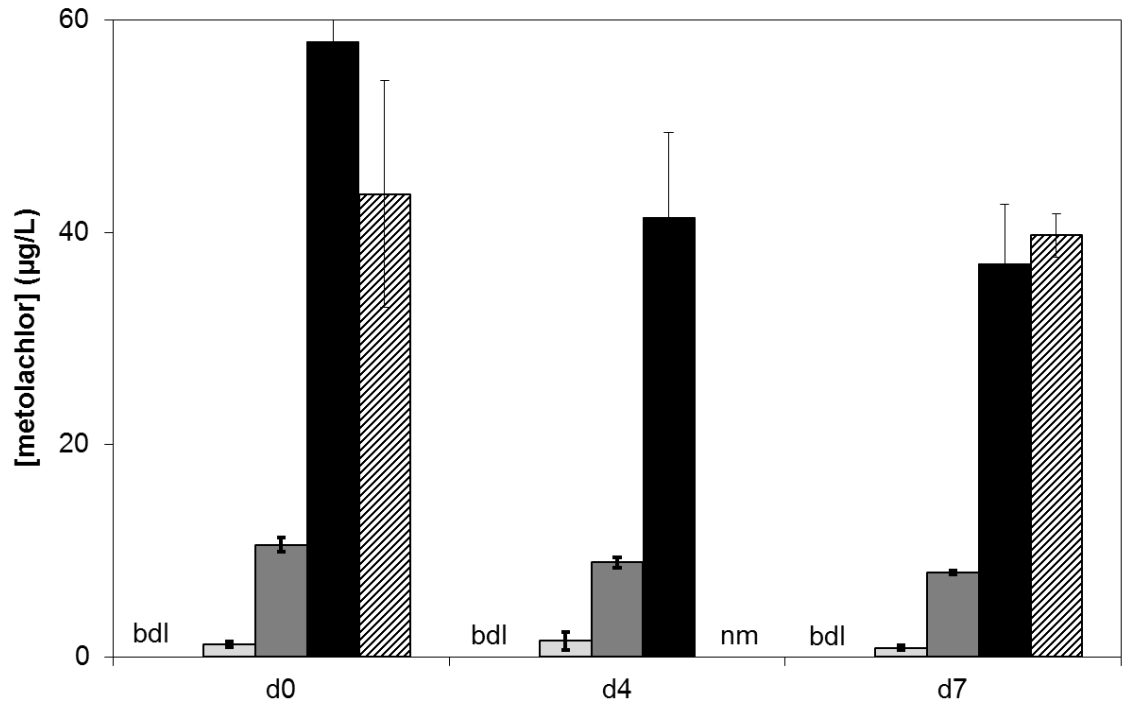

Figure 5 


\begin{tabular}{|l|l|l|l|l|l|}
\hline C0_r1 & C0_r1 & C1_r1 & C1_r2 \\
\hline C0_r2 & & & & \\
\hline C0_r4 & C0_r3 & C0_r3 & C1_r2 & C1_r2 \\
\hline C2_r1 & C0_r4 & C0_r4 & C1_r3 & C1_r3 & C1_r3 \\
\hline C2_r2 & C2_r1 & C2_r2 & C3_r1 & C3_r1 \\
\hline C2_r3 & C2_r2 & C2_r2 & C3_r2 & C3_r2 & C3_r2 \\
\hline
\end{tabular}

Supplementary information: Individual trajectories of G. gracile: projection of 260 video frames from a 10-s video from samples collected day 3. C0 to $\mathrm{C} 3$ indicate the treatment and $\mathrm{r} 1$ to $\mathrm{r} 4$ different replicates. Scale bar: $100 \mu \mathrm{m}$. 